\section{Retrieval of Information after Use of Marihuana}

THERE is anecdotal and experimental evidence that human memory is adversely affected by smoking marihuana ${ }^{1,2}$ but it remains to be determined where in the memory system this impairment occurs. In particular, does marihuana interfere with the encoding or registration of information in the memory or with the retrieval of information once it has been stored? This study is a preliminary investigation of the effects of marihuana on the retrieval aspect of memory.

Adult men and women between 21 and 30 were invited to take part in an experiment dealing with memory. Volunteers were asked whether they had previously used marihuana and only those admitting to such usage were then asked whether they wished to participate in one of the conditions of the experiment, that was to be given marihuana. Those not admitting usage were never given this option.

The experiment ${ }^{3,4}$ involved the reading, to individual subjects, of fifteen lists of ten words each. Immediately after each ten word list, the subject was required to recall, in any order, as many of the words as he could remember; this tested immediate free recall (IFR). They were allowed $1 \mathrm{~min}$ for this, after which the experimenter began to read the next list.
The Mann-Whitney test indicated that the groups also did not differ on the DFR task or on the number of "old" words correctly recognized as being "old" (that is, the number of "hits"). Subjects given marihuana, however, reported significantly more "new" items as being "old" ("false alarms") than did controls $(U=15, P<0.01)$. If the principles of signal detection theory ${ }^{7}$ are applied to the recognition task, it is possible to examine the ratio of "hits" to "false alarms" on the basis of the subject's true sensitivity $\left(d^{\prime}\right)$ independent of any motivational factors or response biases which might have affected his discrimination between items, and it is also possible to determine how stringent a criterion $(\beta)$ the subject uses in making his decision.

Analysis of these two indices indicates that not only does marihuana impair sensitivity or acuity in this type of discrimination task, it also tends to lower significantly the criterion on which he bases his decisions (Table 1). On the other hand, the scores from the Jackson ${ }^{5}$ achievement motivation scales did not differ significantly for the two groups, which suggests that although marihuana lowers the subject's criterion, he, or she, still wishes to do as well on the experimental tasks as the control subject who has not been given marihuana.

The non-significant results of the DFR test suggest that marihuana does not interfere with the retrieval of information

Table 1 Effects of Marihuana on Free Recall, Recognition and Achievement Motivation

$\begin{array}{lccccccc}\text { Condition } & \text { Hits } & \text { False alarms } & d^{\prime} & \beta & \text { IFR } & \text { DFR } & \text { Achievements } \\ \text { Control } & 63.5 & 8.7 & 1.068 & 2.560 & 100.6 & 13.9 & 11.1 \\ \text { Marihuana } & 77.7 & 38.9 & 0.667 & 1.209 & 91.9 & 15.2 & 10.4 \\ & \mathrm{U}=31 & \mathrm{U}=15 & \mathrm{U}=1 & \mathrm{U}=13 & \mathrm{U}=8 & \mathrm{U}=36 & \mathrm{U}=41 \\ & \text { n.s. } & P<0.01 & P<0.03 & P<0.01 & \text { n.s. } & \text { n.s. }\end{array}$

After recall of the last list, experimental subjects smoked one marihuana cigarette (with an undetermined tetrahydrocannabinol content) for about $5 \mathrm{~min}$. During the remainder of the interval before retesting, subjects were free to relax, read, or eat food that had been provided for them. Controls were treated exactly alike except that they were given no marihuana. Twentyfive minutes after the last list had been read to them, subjects were given 5 min to write out as many of the words in the previous lists as they could remember; this tested delayed free recall (DFR). The subject was then given a list of three hundred words containing the one hundred and fifty "old" words interspersed with the same number of "new" words, and asked to encircle all words which he felt had been on the lists previously read to him. After completing this task, the Jackson personality research form (BB) ${ }^{5}$ was administered to each subject to determine whether there were any differences between groups in their responses to the "achievement motivation" statements as a result of smoking marihuana. Jackson ${ }^{5}$ has defined achievement motivation as a willingness "to put forth effort to attain excellence". The purpose of this questionnaire was to find out whether subjects in the marihuana group were less motivated to do well on the recall and recognition tasks. As a result, any differences obtained would be attributable not so much to impairment of retrieval processes, but rather to the fact that subjects in the marihuana group are not willing to put forth the effort needed to perform well on the memory tasks.

Of the twenty-four volunteers, ten subjects per group were matched as closely as possible on the basis of their performance in the IFR test. A Mann-Whitney analysis ${ }^{6}$ indicated that the matching had resulted in no significant differences between groups on this initial, pre-treatment task. These mean scores, along with those from the DFR, recognition, and motivation tasks, are presented in Table 1. already stored in the memory. This then suggests that any impairment in memory caused by marihuana occurs because information fails to become encoded in the memory stores and therefore is not available for retrieval. We are examining this possibility at present.

To refer to the recognition task, however, it is clear that marihuana renders the individual less sensitive in discrimination problems involving a delayed response task. The "hit" and "false alarm" rates indicate that the marihuana and control groups were separated only by the number of "new" items each was willing to accept as "old". In other words, subjects under the influence of marihuana were as capable of picking out "old" items from the lists as the controls, but were less inclined to reject "new" items. This increased willingness to accept, or decreased tendency to reject, is similarly reflected in the lower criterion scores of subjects under the influence of marihuana.

ERnest L. Abel

Department of Psychology, University of Toronto

Received February 17, 1971.

1 Abel, E. L., Nature, 227, 1151 (1970).

2 Tart, C. T., Nature, 226, 701 (1970).

3 Cohen, R. L., J. Verbal Learning and Verbal Behavior (in the press).

4 Craik, F. I. M., J. Verbal Learning and Verbal Behavior, 9, 143 (1970).

5 Jackson, D. N., Personality Research Form (Research Psychologists Press, Goshen, New York, 1966).

6 Siegel, S., Nonparametric Statistics (McGraw-Hill, New York, 1956).

${ }^{7}$ Green, D. M., and Swets, J. A., Signal Detection Theory and Psychophysics (Wiley, New York, 1966). 